Centerfor Quality and Productivity Improvement

University of Wisconsin

610 Walnut Street

Madison, Wisconsin 53705

(608) 263-2520

(608) 263-1425 FAX

quality@engr.wisc.edu

Report No. 181

\title{
Process-oriented Tolerancing for Multi-station Assembly Systems
}

Yu Ding, Jionghua Jin, Dariusz Ceglarek, Jianjun Shi

October 2002

The Center for Quality and Productivity Improvement cares about your reactions to our reports. Please direct comments (general or specific) to: Reports Editor, Center for Quality and Productivity Improvement, 610 Walnut Street, Madison, WI 53726; (608) 263-2520. All comments will be forwarded to the author(s). 


\title{
Process-oriented Tolerancing for Multi-station Assembly Systems
}

\section{Yu Ding}

Dept. of Industrial Engineering

Texas A\&M University

College Station, TX 77843

Email: yuding@iemail.tamu.edu

\section{Dariusz Ceglarek}

Dept. of Industrial Engineering University of Wisconsin - Madison Madison, WI 53706

Email: darek@engr.wisc.edu
Jionghua Jin

Dept. of Systems and Industrial Engineering

The University of Arizona

Tucson, AZ 85721

Email: jhjin@sie.arizona.edu

\section{Jianjun Shi}

Dept. of Industrial and Operations Engineering

The University of Michigan

Ann Arbor, MI 48109

Email: shihang@umich.edu

\begin{abstract}
In multi-station manufacturing systems, the quality of final products is significantly affected by both product design as well as process variables. However, historically tolerance research primarily focused on allocating tolerances based on product design characteristics of each component. Currently, there are no analytical approaches to optimally allocate tolerances to integrate product and process variables in multi-station manufacturing processes at minimum costs. The concept of process-oriented tolerancing expands the current tolerancing practices, which bound errors related to product variables, to explicitly include process variables. The resulting methodology extends the concept of "part interchangeability" into "process interchangeability," which is critical in increasing requirements related to the suppliers selection and benchmarking.

The proposed methodology is based on the development and integration of three models: tolerance-variation relation, variation propagation, and process degradation. The tolerance-variation model is based on a pin-hole fixture mechanism in multi-station assembly processes. The variation propagation model utilizes a state space representation but uses a station index instead of time index. Dynamic process effect such as tool wear is also incorporated into the framework of processoriented tolerancing, which provides the capability to design tolerances for the whole life-cycle of a production system. Tolerances of process variables are optimally allocated through solving a nonlinear constrained optimization problem. An industry case study is used to illustrate the proposed approach.
\end{abstract}




\section{INTRODUCTION}

Manufacturing operations are inherently imperfect in fabricating parts and assembly-products. Product imperfections were first described in the concept of part interchangeability and introduced and implemented in early mass production, which further led to the development of product tolerancing. Tolerancing is one primary means to guarantee part interchangeability. There is a significant body of literature related to tolerancing methods and its applications. Summaries of the state-of-the-art, the most recent developments, and the future trends in tolerancing research can be found in Bjorke (1989) and Zhang (1997) as well as in a number of survey papers such as Chase and Parkinson (1991), Roy et al. (1991), Jeang (1994), Ngoi and Ong (1998), and Voelcker (1998).

In general, product errors accumulate during the whole manufacturing process and can be divided into two major stages (Fig. 1): (i) part fabrication processes, such as stamping process (forming processes), machining process (material removal processes), or rapid prototyping (material deposition processes) that transforms raw material into components or parts; and, (ii) the assembly process that joins all parts into the final product.

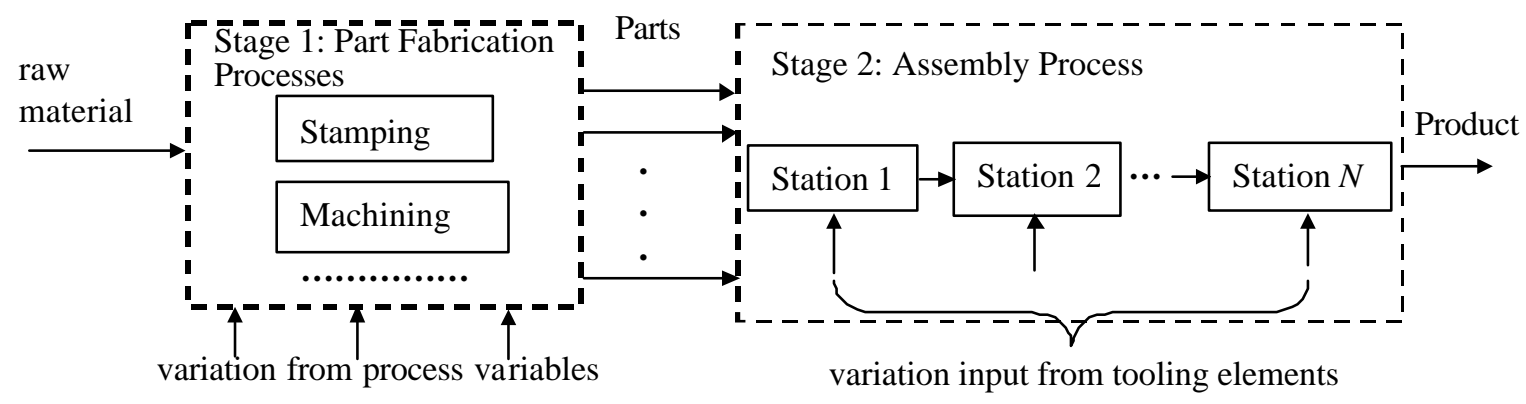

Figure 1. Schematic diagram of a manufacturing process

Traditionally, tolerance analysis and synthesis in both stages have been studied in the context of product variables, i.e., they focused on part interchangeability. We feel that there is a tremendous need to further expand it to the interchangeability of manufacturing processes. This is becoming increasingly apparent with growing requirements related to manufacturer best practices, suppliers selection and benchmarking (where each supplier may use different process to manufacture the same product) or outsourcing. Tolerancing has the potential of being an important tool in such developments. We propose to extend the scope of tolerancing to explicitly include process 
variables in manufacturing processes.

\subsection{Two Stages of Traditional Tolerancing}

Tolerance synthesis is usually conducted separately for part fabrication and product assembly (Zhang, 1996). Tolerancing at Stage 2 is often called tolerancing for assembly, i.e., tolerance requirements of a finished product are allocated to dimensions of individual parts. The allocated part tolerances are called design tolerances. According to Voelcker (1998), tolerancing-forassembly "has been the predominant concern in most product designs for at least half a century."

Tolerancing at Stage 1 is to further convert design tolerances into manufacturing tolerances, i.e., the tolerances of intermediate working dimensions in part fabrication processes, such as in machining processes. The primary methodologies used for tolerancing in Stage 1 are based on tolerance charting (Ngoi and Ong, 1993, 1999). For the purpose of illustration, let us consider the following example in Fig. 2. The product design dimensions (D1,D2) with their tolerances $(\mathrm{T} 1, \mathrm{~T} 2)$ are shown in Fig. 2(a). The manufacturing process involves two operations to remove materials and generate resultant dimensions (Fig. 2(b)). Accordingly, there are two working dimensions (WD1,WD2) that are the direct results of these two manufacturing operations. The purpose of tolerance allocation at stage-1 (using tolerance charting) is to establish the relation between D1, D2 and WD1,WD2 and to transform design tolerances T1,T2 to manufacturing tolerances WT1,WT2.

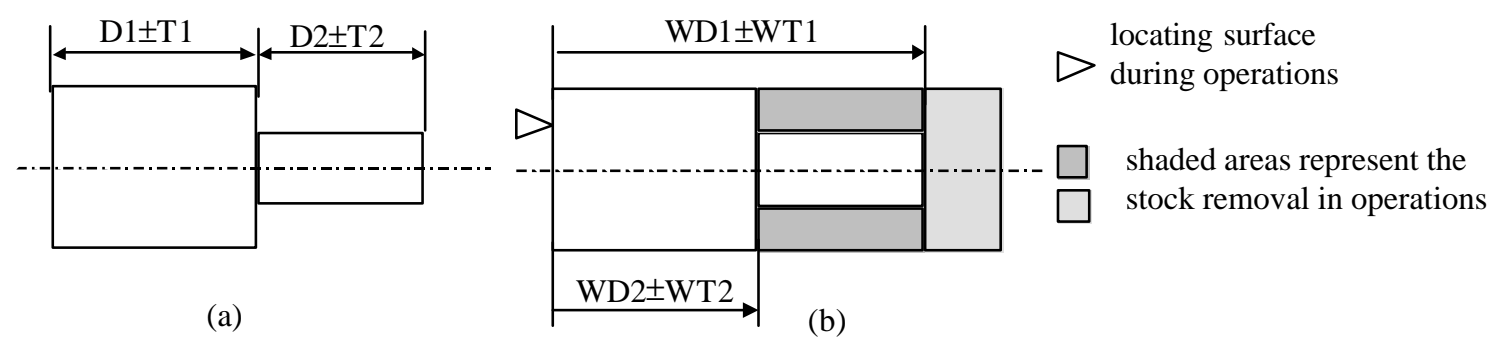

Figure 2. Design tolerance and manufacturing tolerance

\subsection{Product Variables vs Process Variables}

Product variables are those key variables which characterize the design that satisfies specified product functional requirements. Product variables are also called key product characteristics (KPCs). They include design dimensions of finished assemblies/parts as well as working dimensions of intermediate workpieces. The dimensions on a product blueprint are considered to be 
product variables because they are the resultant variables of manufacturing actions instead of direct descriptions of process status. A closer examination reveals that working dimensions (WD1,WD2) and their tolerances (WT1,WT2) are product variables.

On the other hand process variables are not part of product information. Process variables are those key variables, which characterize the process that controls specified product design variables. Process variables are also called key control characteristics (KCCs). They describe the working condition of tooling elements that are used to hold or fabricate a workpiece during machining or assembly processes.

Let us consider another example as shown in Fig. 3 to elaborate the meaning of process variable. This example is similar to the process studied in Rong and Bai (1996) and Choudhuri and DeMeter (1999). Here we examine how the variation caused by locator tolerance PT1 affects the quality of a machined part. The dimension and tolerance of the locator are indicators of the working condition of a fixture element rather than the descriptions of the machined part. Thus, the dimension and tolerance of the locator (PD1, PT1) are process variables.

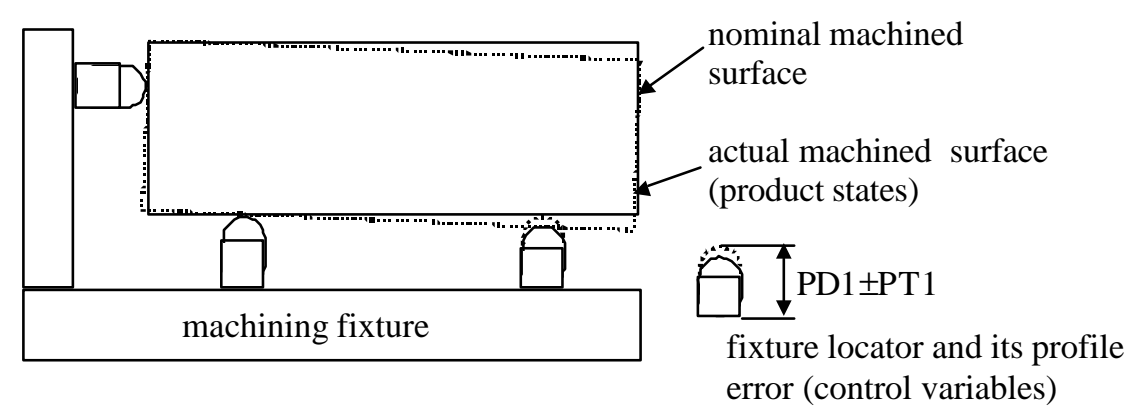

Figure 3. The effect of process variable (locator error) on product quality

The difference between product variables (WD1,WD2) and process variable (PD1) can be explained as such: tolerances of process variables describe the cause of manufacturing imperfection while tolerances of product variables describe the effect of variations of process variables on product dimension or other quality characteristics. In more complex processes with multiple stations and/or operations, the tolerance of product variables is also affected by variations of process variables of earlier operations/stations. For example, when the locating surface (indicated by a triangle) in Fig. 2 is subject to profile errors, the working tolerances WT1 and WT2, which use the 
indicated surface as the machining datum, will be affected by the propagation of variation from previous operations that generate the locating surface.

Process variables that were discussed in the above examples are dimensional or geometrical variables. However, process variables generally can include a broad category of physical variables associated with manufacturing processes (in both part fabrication and assembly processes).

\subsection{Product-oriented Tolerancing vs Process-oriented Tolerancing}

Although it is common understanding that tolerancing controls process imperfections and inaccuracies, process information included in tolerancing-for-assembly at Stage 2 is actually limited to some heuristics information presented implicitly in the form of cost-tolerance functions, e.g., information about machine availability or capability in a combined process (Fig. 7.2 in Bjorke, 1989). Thus, the tolerancing-for-assembly can be described as "product-oriented" tolerancing.

Process information such as manufacturing sequence and tool condition is seemingly included in tolerance charting at Stage-1. However, based on discussions in the previous section, tolerance charting is still product-oriented since the intermediate working dimensions (WD1,WD2) and their tolerances are product variables. In other words, process information is actually included in productoriented tolerancing in indirect or implicit ways.

In this paper, instead of considering only product variables, we propose to explicitly include process variables, such as the locator dimension and tolerance in Fig. 3, in the tolerancing scheme. To differentiate this approach from traditional tolerancing, we call it process-oriented tolerancing. Tolerancing techniques studied in Rong and Bai (1996) and Choudhuri and DeMeter (1999) can be considered as process-oriented.

It was a mainstream perception that process variables are not major variation contributors in assembly processes. Assembly research often assumes that variations originate from individual components while tools used in assembly processes only function as an auxiliary mechanism to roughly hold and position parts before they are assembled. One may quickly conclude that process-

oriented tolerancing is not an applicable concept in assembly processes. However, the conclusion is not true. In general, assembly processes can be classified into two categories (also refer to 
Mantripraganda and Whitney (1999) for this classification): (i) Type-I assembly, where parts are assembled through part-to-part mating surfaces, which is consistent with the aforementioned perception; and (ii) Type-II assembly, where parts are positioned by fixtures while there is no partto-part interference to prevent part from being freely positioned by the fixture. Figure 4 shows examples of both Type-I and Type-II assembly processes. A significant amount of research in tolerancing-for-assembly considered Type-I assembly processes. Much less research exists on tolerancing of Type-II assembly processes. However, there is a large class of Type-II assembly processes such as automotive or aircraft body assembly or printed circuit board assembly processes.

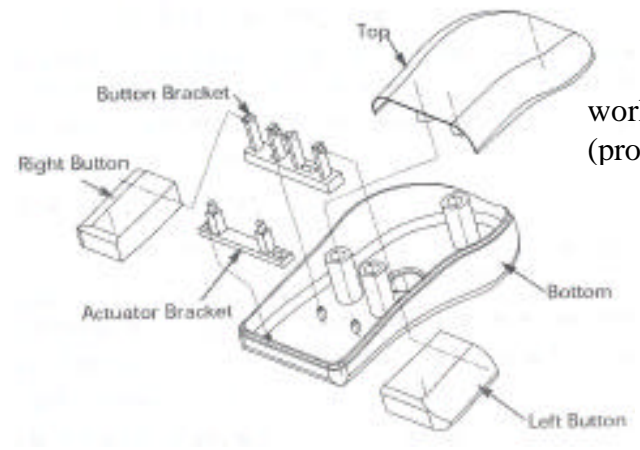

(a) Type-I Assembly

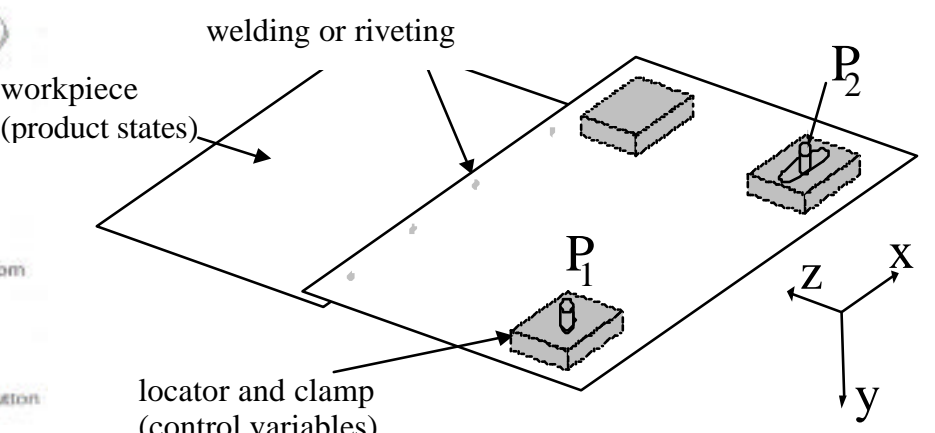

(b) Type-II Assembly

Figure 4. Type-I and Type-II assembly

The final dimensional accuracy of Type-II assemblies are determined during the assembly process while the accuracy of Type-I assemblies is determined mostly by the precedent fabrication processes of each part. In contrast to Type-I assembly, the product quality of Type-II assemblies are greatly affected by variations of tooling elements, especially that of fixture locators (Celgarek and Shi, 1995; Cunningham et al. 1996). Tolerance analysis and synthesis of tooling elements for Type-II assembly processes is another example of process-oriented tolerancing. The reasons that a shift to the process-oriented tolerancing from the traditional product-oriented tolerancing is desirable lie in the following aspects:

(1) Variations of process variables are root causes of product quality-related problems. Process variables are controllable factors in manufacturing process. Process-oriented tolerancing exerts a direct control on those major variation contributors. Tooling elements that are represented by process variables can potentially be connected with realtime minimum-variance controllers during 
production to achieve a higher performance.

(2) Proposed process-oriented tolerancing is based on a generic mathematical model of variation propagation in multi-station assembly processes. It provides more systematic and unified approach for different types of manufacturing processes. In contrast, the tolerance charting approach is based on graphical description and is mainly developed for stock-removal processes. The model framework of tolerance charting is not generic enough to expand tolerance charting to other part fabrication processes, for instance, progressive (multi-station) sheet metal stamping.

(3) The direct inclusion of process variables into tolerance models can potentially lead to the integration of tolerancing with reliability analysis and process maintenance strategies. Process variables provide stochastic information about process dynamics, for example, tooling wear-out. Proposed process-oriented tolerancing can incorporate tooling wear-out variables and lead to a lifecycle tolerance design. Although the effect of tool wear on product quality was previously studied in machining processes (Quesenberry 1988; Jensen and Vardeman, 1993; Fraticelli et al. 1999), the discussion in Section 2.4 shows that process-oriented tolerancing requires a different approach.

\subsection{Research Challenges in Process-oriented Tolerancing}

Process-oriented tolerancing is a largely under-investigated area even though the variation of process variables has direct and tremendous effect on product quality in both part fabrication and assembly processes. The diversity of process variables and associated complexity is one of the reasons that process variables are seldom included explicitly in tolerancing schemes. Given so many sources of manufacturing process errors, initially it seems infeasible to directly study the tolerances for various process variables. In this paper we utilized the state-of-the-art development of identification and analysis of variation sources in manufacturing processes, especially in machining

and Type-II assembly processes (Slocum, 1992; Soons et al. 1992; Cai et al. 1996; Mou 1997). Those developments are enabling forces behind the proposed process-oriented tolerancing.

Another technical challenge of performing process-oriented tolerancing results from the complex fashion of variation propagations in multi-station or multi-stage operations. The variation propagation is conceptually similar to the traditional tolerance stack-up but generally much more 
complicated. For instance, if compliant parts are involved in an assembly process, the product variation level could even decrease when the rigidity of a compliant-assembly increases. Generally, we need to identify (i) the variation transmitted from tooling elements to a product on individual stations; and, (ii) the variation induced when the intermediate product is transferred from one station to another. In order to provide a unified framework that makes the process-oriented tolerancing applicable for different multistation manufacturing processes, research efforts are in need to systematically model the propagation of variation in a multistation process. We utilize the matrix perturbation theory developed in robotics research (Veitschegger and Wu, 1986; Whitney et al., 1994) to describe complex variation transmission and adopt a state space representation to recursively represent station-to-station variation propagation. A few multi-station variation propagation models have been developed for rigid-part assembly processes (Mantripragada and Whitney 1999; Jin and Shi, 1999; Ding et al., 2000; Lawless et al. 1999), compliant-part assembly process (Camelio et al., 2001), machining processes (Djurdjanovic and Ni, 2001; Agrawal et al. 1999), and stretch forming processes (Suri and Otto, 1999). With these developments, processoriented tolerancing can be extended to various ge neral multi-station manufacturing processes under a unified framework.

The major contribution of this paper resides in two aspects: conceptually extend the scope of tolerancing research to explicitly include process variables in tolerancing schemes and develop tolerance synthesis method for process life-cycle design in a multi-station assembly system with different fixture setups rather than on a single station with one-time fixture set-up. We consider our research effort as one of the initial yet important steps in addressing the general issue of processoriented tolerancing in multi-station manufacturing processes.

The outline of the paper is as follows. In Section 2, the general framework of process-oriented tolerance synthesis is presented and the detailed models are materialized for a multi-station assembly process. Section 3 illustrates the proposed technique using an industrial case study of automotive body assembly process. Finally, the methodology is summarized in Section 4 . 


\section{PROCESS-ORIENTED TOLERANCING IN MULTI-STATION ASSEMBLY}

\subsection{Overview}

In the introduction, we illustrated the difference between process variables and product variables and made the distinction between product-oriented tolerancing and process-oriented tolerancing. Following the manufacturing process flow shown in Fig. 1, process-oriented tolerancing can have three scenarios, presented below with a short analysis:

(1) Process-oriented tolerancing of part fabrication processes. Research under this scenario was conducted for machining processes by Rong and Bai (1996) and Choudhuri and DeMeter (1999). However, in their papers, only tolerance analysis (variation simulation) at a single workstation with one-time tool setup is discussed. The proposed process-oriented tolerancing includes not only tolerance analysis but also tolerance synthesis in multi-station processes with multiple tool set-ups.

(2) Process-oriented tolerancing of assembly processes. Existing papers on tolerancing for TypeII assembly (Liu et al. 1996; Ceglarek and Shi, 1997) focused on the effect of flexibility of compliant-parts on tolerance analysis. Effects from tooling elements were not included in their study. Commercial software packages such as 3-DCS (DCS, 2000) and VSA (VSA, 1998) can perform variation simulation in the forward direction. Tolerances synthesis as an inverse problem is difficult for a simulation software to solve. The tolerance synthesis needs an analytical model to describe the propagation of variation in a multi-station process.

(3) Process-oriented tolerancing for an integrated fabrication and assembly process. The third scenario is an integration of the two aforementioned scenarios, i.e., simultaneously allocate tolerances to tooling elements in the assembly process and process variables in the part fabrication process. There were efforts to integrate the allocation of design tolerances and manufacturing tolerances (both of product variables) in Stages 1 and 2 (Zhang, 1996). Our proposed methods possesses a similar philosophy but extends the scope of tolerancing to process variables.

The detailed development presented in this paper is focused on the second scenario, i.e., how to optimally allocate tolerances to fixture elements in a multistation assembly process. The choice is 
made based on the understanding that little research has been reported in this sub-area of processoriented tolerancing. However, since we employ a general state-space approach in modeling variation propagation of multi-station processes, the proposed approach can be readily extended to many different processes such as machining or stamping processes.

A schematic diagram is shown in Fig. 5 to demonstrate interrelations between tolerances, quality, and cost in a multi-station manufacturing process. The cost is associated with the tolerances assigned to both process and product variables. Variations of these variables determined by their tolerances will affect the quality of the final product. The variation of process variables contributed from different manufacturing stations is the focus of this paper. The variation of product variables, i.e., the variation of each component/part resulting from precedent processes, is treated as an initial variation condition to the current assembly process.

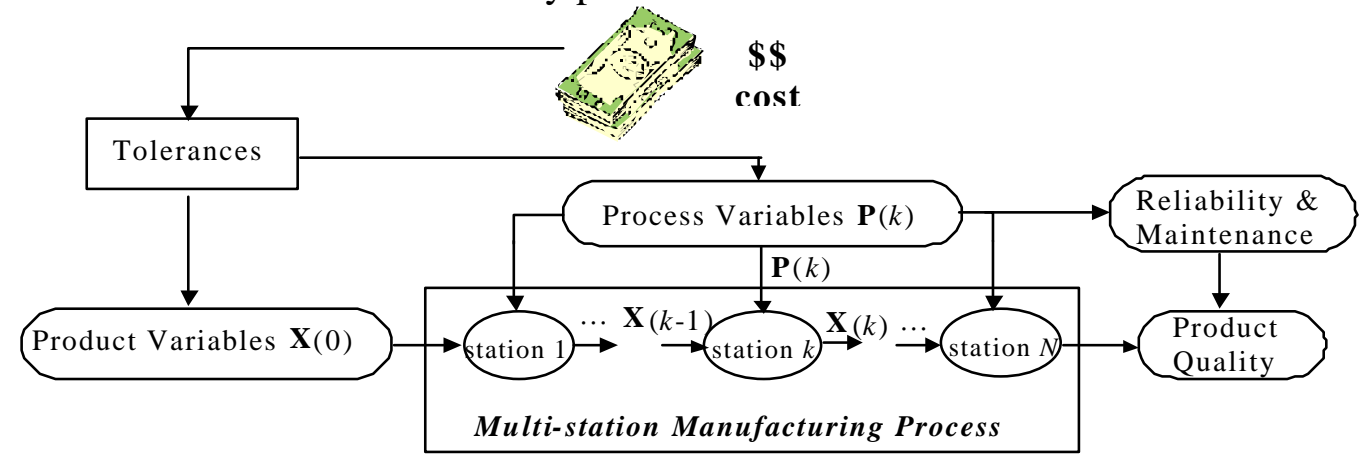

Figure 5. Overview of process-oriented tolerance synthesis

As we pointed out in Introduction, process variables provide dynamic process information (for example, the information related to a tool wear process). Thus, process variables are strongly related to process reliability and corresponding maintenance policies. If tolerances are allocated without considering tooling degradation, product quality can only be guaranteed at the very initial stage of a production. However, quality criteria should be satisfied not only during the initial stage of a production but also during the whole life cycle of a production system. Currently, for numerous real production systems, maintenance service is conducted based on a fixed time schedule. For example, all locating pins at assembly stations are replaced every half year. In this case, the initial tolerances need to be tighter to accommodate tooling degradation between maintenance schedule to avoid out-of-specification products. Mathematically, the optimal tolerance 
$\mathbf{T}^{*}$ can be formulated as the following constrained optimization

$$
\begin{aligned}
& \mathbf{T}^{*}=\min _{\mathbf{T}} C_{T}(\mathbf{T}) \\
& \text { subject to } g\left(\mathfrak{I}_{Q}(\mathbf{T}, t), C\right) \geq 0 \text { for }\left\{t: 0<t<t_{m}\right\},
\end{aligned},
$$

where $C_{T}$ represents the cost function, $\mathbf{T}$ is the tolerance vector of selected key process variables, $g(\cdot, \cdot)$ is a constraint function to be determined from the nature of a quality measure, $\mathfrak{I}_{Q}(\cdot, \cdot)$ is a given measure or index of product quality, $C$ is the threshold of specified product quality, $t$ is the time, and $t_{m}$ represents the maintenance time period.

The cost function $\left(C_{T}\right)$ is determined by tolerances assigned to process variables. Generally, the tighter the tolerance, the higher the cost of satisfying it. The reciprocal function and negative exponential function are widely used as cost functions ( $\mathrm{Wu}$ et al. 1988). However, process variables are very diversified and are not limited to describing geometrical relations, which may create difficulty in selecting the most appropriate cost function of tolerance. The choice of cost function of process variables strongly depends on the physics of those variables. The selection of cost function for non-geometrical variables is not discussed in this paper.

The second question is how to relate the tolerances $(\mathbf{T})$ to the product quality index $\left(\mathfrak{I}_{Q}(\cdot, \cdot)\right)$, which is part of the constraint function $(g(\cdot, \cdot))$. The development of such a constraint function needs several essential models shown in Fig. 6. Tolerances are first related to the variations of process variables. Product variation-stream propagates along a production line with contribution and accumulation from process variables at each station. Eventually, some proper measure is exerted to compare product variation with a specified product quality index. Overall, there are four key elements to realize the above optimization formulation: a variation propagation model; a tolerance-variation relation; a process degradation model; and a cost function. 


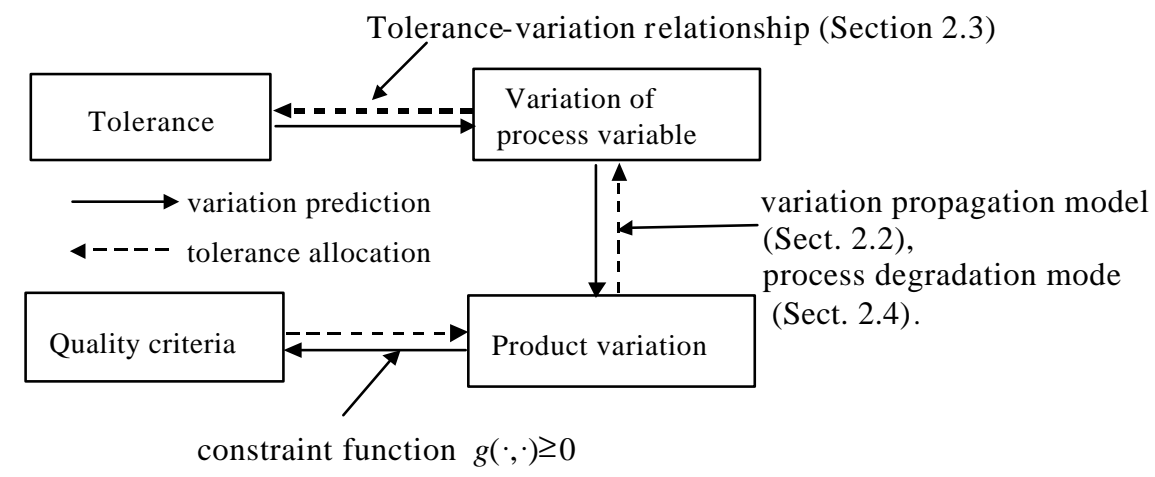

Figure 6. Relationship between tolerance and quality

\subsection{State Space Model of Variation Propagation}

A multi-station assembly process such as automotive body assembly is described in detail in (Ceglarek et al., 1994). The modeling of fixture-related variation propagation in such an assembly process has been studied by Shiu et al. (1997), Jin and Shi (1999), and Ding et al. (2000). Two major variation contributors were identified: (1) fxture-induced variation at each single station caused by fixture locators failures (Fig. 7(a)); for example for 3-2-1 fixture layout with two locators $\mathrm{P}_{1}$ and $\mathrm{P}_{2}$, the failure of locator $\mathrm{P}_{2}$ represented as $\delta \mathrm{P}_{2}(z)$ is the part deviation in $Z$-direction at locator $\mathrm{P}_{2}$; and (2) the reorientation-induced variation caused by possible locating layout change between stations (Fig. 7(b)). The first factor, the fixture-induced variation at each station, is affected by the geometry of fixture locating layout, i.e., the coordinates of fixture locators. The second factor, the reorientation-induced variation, is affected by the magnitude of fixture locating layout changes between stations.

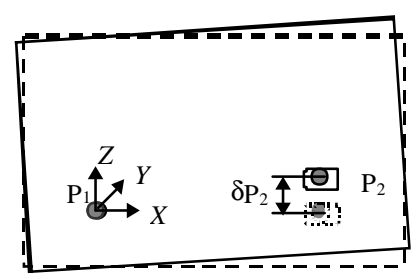

(a)

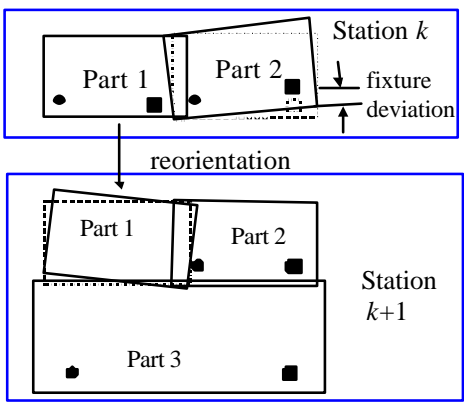

(b)

Figure 7. Variation induced at a single station and across stations

These two variation contributors and their propagation can be modeled in an $\mathrm{N}$-station assembly process shown in Fig. 8 by using a state space representation (Jin and Shi 1999; Ding et al., 2000). 
The basic idea of developing the state space variation model is to consider the multi- station process as a sequential dynamic system but replace the time index in the traditional state space model with a station index. The state space model includes two equations:

$$
\begin{aligned}
& \mathbf{X}(k)=\mathbf{A}(k-1) \mathbf{X}(k-1)+\mathbf{B}(k) \mathbf{P}(k)+\mathbf{W}(k), \\
& \mathbf{Y}(k)=\mathbf{C}(k) \mathbf{X}(k)+\mathbf{V}(k),
\end{aligned}
$$

where the first equation, known as the state equation, suggests that the part deviation at station $k$ is influenced by the accumulated deviation up to station $k-1$ and the deviation contribution at station $k$; the second equation is the observation equation.

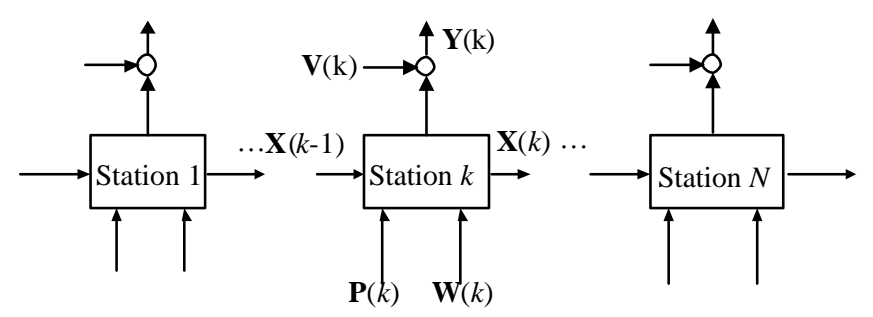

Figure 8. Diagram of an assembly process with $N$ stations

In the above equations, $\mathbf{X}(k)$ is the product quality information (e.g., part dimensional deviations) after operations at station $k ; \mathbf{P}(k)$ is the process variation contributed at station $k$; product measurements at KPCs at station $k$ are included in $\mathbf{Y}(k)$; and $\mathbf{W}(k)$ and $\mathbf{V}(k)$ are unmodeled errors and sensor noises, respectively. Matrices $\mathbf{A}(k)$ and $\mathbf{B}(k)$ include information regarding process design such as fixture layout on individual stations and the change of fixture layouts across stations, and $\mathbf{C}(k)$ includes sensor deployment information (the number and location of sensors on station $k$ ). The corresponding physical interpretation of $\mathbf{A}, \mathbf{B}$, and $\mathbf{C}$ is presented in Table 1, where $\mathbf{F}(k, j) \equiv \mathbf{A}(k-1) \cdots \mathbf{A}(j)$ and $\mathbf{F}(j, j) \equiv \mathbf{I}$ (I is an identity matrix with appropriate dimensions) and the detailed expression can be found in Jin and Shi (1999) and Ding et al. (2000).

Table 1. Interpretation of system matrices

\begin{tabular}{|c|l|l|l|l|}
\hline Symbol & \multicolumn{1}{|c|}{ Name } & Relationship & \multicolumn{1}{|c|}{ Interpretation } & Assembly Task \\
\hline $\mathbf{A}$ & Dynamic matrix & $\mathbf{X}(k-1) \stackrel{\mathbf{A}(k-1)}{\longrightarrow} \mathbf{X}(k)$ & $\begin{array}{l}\text { Change of fixture layout } \\
\text { between two adjacent stations }\end{array}$ & $\begin{array}{l}\text { Assembly } \\
\text { transfer }\end{array}$ \\
\hline $\mathbf{F}(k, i)$ & $\begin{array}{l}\text { State transition } \\
\text { matrix }\end{array}$ & $\mathbf{X}(i) \stackrel{\mathbf{F}(k, i)}{\longrightarrow} \mathbf{X}(k)$ & $\begin{array}{l}\text { Change of fixture layout } \\
\text { among multiple stations }\end{array}$ & $\begin{array}{l}\text { Assembly } \\
\text { transfer }\end{array}$ \\
\hline $\mathbf{B}$ & Input matrix & $\mathbf{P}(k) \stackrel{\mathbf{B}(k)}{\longrightarrow} \mathbf{X}(k)$ & Fixture layout at station $k$ & Part positioning \\
\hline $\mathbf{C}$ & $\begin{array}{l}\text { Observation } \\
\text { matrix }\end{array}$ & $\mathbf{X}(k) \stackrel{\mathbf{C}(k)}{\longrightarrow} \mathbf{Y}(k)$ & Sensor layout at station $k$ & Inspection \\
\hline
\end{tabular}


Suppose that there is only an end-of-line observation, that is, $k=N$ in the observation equation of Eq. (3). Then, we have

$$
\mathbf{Y}(N)=\sum_{k=1}^{N} \mathbf{C}(N) \mathbf{F}(N, k) \mathbf{B}(k) \mathbf{P}(k)+\mathbf{C}(N) \mathbf{F}(N, 0) \mathbf{X}(0)+\mathbf{e}
$$

Here, $\mathbf{X}(0)$ corresponds to the initial condition, resulting from the imperfect manufacturing of stamped parts, and $\mathbf{e}$ is the summation of all modeling uncertainty and sensor noise terms (modeled by W's and V's). Moreover, it was assumed that this process involves sheet metal assembly with only lap-lap joint and thus, the stamping imperfection of part dimensions will not affect the propagation of variations. Then, we can set initial conditions to zero. The uncertainty term e can be neglected in design stage given the fact that a simulation study presented in Ding et al. (2000) showed that the uncertainty term $\mathbf{e}$ accounts for $0.02 \%$ extra variation in a standard three-station automotive body assembly process with 3-2-1 fixtures. The variation propagation can then be approximated as

$$
\mathbf{K}_{Y}=\sum_{k=1}^{N} \boldsymbol{?}(k) \mathbf{K}_{P}(k) \boldsymbol{?}^{T}(k),
$$

where $\mathbf{K}_{Y}$ and $\mathbf{K}_{P}(k)$ represent the covariance matrices of $\mathbf{Y}(N)$ and $\mathbf{P}(k)$, respectively, and $?(k) \equiv \mathbf{C}(N) \mathbf{F}(N, k) \mathbf{B}(k)$. Based on engineering knowledge, it is known that process variable in this problem is the fixturing error at every assembly station, which is often caused by the clearance of locating pin-hole pairs.

\subsection{Relationship between Tolerance and Variation}

The presented analysis is conducted for part fixturing based on a pin-hole type of locators, which are commonly used in automotive assembly processes. However, similar analysis can also be conducted for other part fixturing locating elements used in different processes. There are two major types of pin-hole locating pair: (1) a 4-way pin-hole locating pair and (2) a 2-way pin-hole locating pair, shown in Fig. 9, where $d_{\text {pin }}$ or $d_{\text {hole }}$ is the diameter of a pin or a hole and $T_{i}$ is the specified tolerance of a clearance, that is, the upper limit of the clearance. 


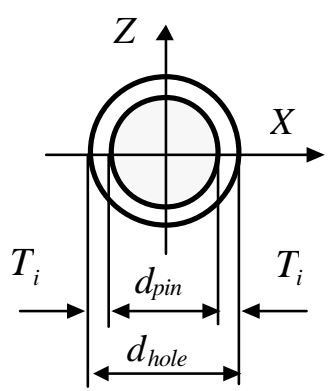

(a) 4-way pin/hole

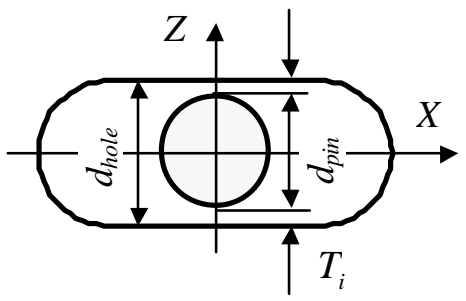

(b) 2-way pin/hole

Figure 9. Diagram of pin/hole locating pairs

A 4-way pin-hole locating pair includes a homogeneous circular hole and controls the motion in both the $X$ and $Z$ directions (Fig. 9(a)). A 2-way pin-hole locating pair consists of a slot and a circular pin and thus, only controls the motion perpendicular to the long axis of the slot, i.e., the $Z$ direction in Fig. 9(b). These two types of locating pairs are used together to position a part during assembly. Due to the free motion along the $X$ axis of a 2-way pin-hole locating pair, the part is not over-constrained in the fixture.

Our primary interest is to study the variations associated with a pin-hole locating pair caused by its clearance. The clearance-induced deviation is shown in Fig. 10. Its geometrical relationship is obtained by Jin and Chen (2001). The deviation of a 4-way locating pair is exemplified in Fig. 10 (a), in which the deviation of $\mathrm{P}_{1}{ }^{\prime}$ (the center of the pin-hole) from $\mathrm{P}_{1}$ (the center of the pin) in both the $X$ and the $Z$ directions are

$$
\begin{aligned}
& \Delta X=\delta \cos \theta, \\
& \Delta Z=\delta \sin \theta,
\end{aligned}
$$

where $\delta$ is the distance between $\mathrm{P}_{1}{ }^{\prime}$ and $\mathrm{P}_{1}$ and $\theta$ is the contact orientation.

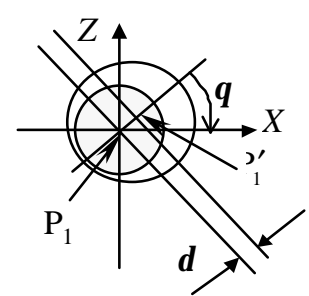

(a)

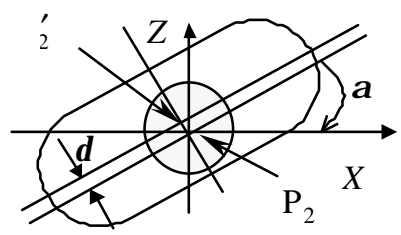

(b)

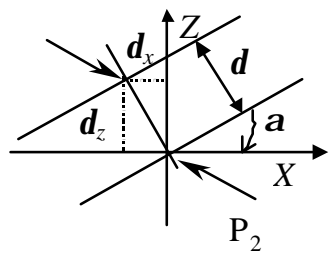

(c)

Figure 10. Clearance-induced deviation

Denoted by $\delta$, the random variable representing the actual clearance in one setup. Then $\delta$ is 
bounded by $\left[0, T_{i}\right]$ since $T_{i}$ is the clearance tolerance. We approximate $\delta$ by a normal distribution $\mathrm{N}\left(\frac{T_{i}}{2},\left(\frac{T_{i}}{6}\right)^{2}\right)$. The clearance of a 4-way locating pair is considered to be homogenous in all directions and thus the orientation angle $\theta$ is of a uniform distribution between 0 and $2 \pi$, i.e., $\theta \sim$ $\mathrm{U}(0,2 \pi)$. Given that $\delta$ and $\theta$ are independent of each other, the statistics regarding $\Delta X$ and $\Delta Z$ are given as:

$$
\begin{aligned}
& \mathrm{E}[\Delta X]=\mathrm{E}[\delta \cos \theta]=\mathrm{E}[\delta] \cdot \mathrm{E}[\cos \theta]=0, \\
& \mathrm{E}[\Delta Z]=\mathrm{E}[\delta \sin \theta]=\mathrm{E}[\delta] \cdot \mathrm{E}[\sin \theta]=0, \\
& \sigma_{X, 4-\text { way }}^{2}=\mathrm{E}\left[\Delta X^{2}\right]=\mathrm{E}\left[\delta^{2}\right] \cdot \mathrm{E}\left[\cos ^{2} \theta\right]=\frac{5 T_{i}^{2}}{36}, \\
& \sigma_{Z, 4-\text { way }}^{2}=\mathrm{E}\left[\Delta Z^{2}\right]=\mathrm{E}\left[\delta^{2}\right] \cdot \mathrm{E}\left[\sin ^{2} \theta\right]=\frac{5 T_{i}^{2}}{36}, \\
& \operatorname{Cov}(\Delta X, \Delta Z)=\mathrm{E}[\Delta X \Delta Z]=\mathrm{E}\left[\delta^{2} \sin \theta \cos \theta\right]=\mathrm{E}\left[\delta^{2}\right] \cdot \mathrm{E}[\sin \theta \cos \theta]=0,
\end{aligned}
$$

where $\mathrm{E}[\cdot]$ is the expectation operator and $\operatorname{Cov}(\cdot, \cdot)$ represents the covariance of two random variables. These equations suggest that the deviations of $\mathrm{P}_{1}{ }^{\prime}$ in both directions have zero mean and the same variances. They are uncorrelated according to Eq. (12).

The geometrical relationship of a 2-way locating pair with orientation angle $\alpha$ shown in Fig. 10 (b) and (c) reads

$$
\delta_{X}=\delta \sin \alpha \cdot \kappa \text { and } \delta_{Z}=-\delta \cos \alpha \cdot \kappa,
$$

where $\delta$ is defined in the same way as before and $\kappa$ is a binary random variable with its value either 1 or -1 . We postulate that if the pin touches the top (or left if $\alpha$ approaches $90^{\circ}$ ) edge of a pin-hole, then $\kappa$ is 1 ; if the pin touches the bottom (or right if $\alpha$ approaches $90^{\circ}$ ) edge of a pin-hole, then $\kappa$ is -1. Also, $\kappa$ is independent of $\delta$. Hence, the variation associated with a 2-way locating pair can be expressed as

$$
\begin{aligned}
& \mathrm{E}\left[\delta_{\mathrm{X}}\right]=\mathrm{E}\left[\delta_{\mathrm{Z}}\right]=0, \\
& \sigma_{X, 2-\text { way }}^{2}=\mathrm{E}\left[\delta^{2} \sin ^{2} \alpha \cdot \kappa^{2}\right]=\frac{5 T_{i}^{2}}{18} \cdot \sin ^{2} \alpha, \\
& \sigma_{Z, 2-\text { way }}^{2}=\mathrm{E}\left[\delta^{2} \cos ^{2} \alpha \cdot \kappa^{2}\right]=\frac{5 T_{i}^{2}}{18} \cdot \cos ^{2} \alpha, \\
& \operatorname{Cov}\left(\delta_{X}, \delta_{Z}\right)=\mathrm{E}\left[\delta^{2} \cos \alpha \sin \alpha \cdot \kappa^{2}\right]=\frac{5 T_{i}^{2}}{18} \cos \alpha \sin \alpha .
\end{aligned}
$$


Equation (17) implies that the deviations of a 2-way locating pair in an arbitrary orientation angle $\alpha$ are correlated. Equations (10), (11), (15), and (16) will be iteratively applied to every pinhole locating pair on each station in a multi-station assembly process so that $\mathbf{K}_{P}(k)$ can be expressed in terms of corresponding fixture tolerances.

Remarks. (i) The model of pin-hole contact discussed here can be considered as a special case of the chain-link models presented in Bjorke (1989) -- the 2-way pin-hole contact is the lumpedmagnitude/lumped-direction case and the 4-way pin-hole is the lumped-magnitude/distributeddirection case. For some other manufacturing processes, other models may be required (for example, distributed-magnitude/distributed-direction as mentioned in Bjorke (1989)); which need to be developed separately from the analysis presented in this paper; (ii) The pin-hole contact in a fixture locating scheme may resemble the geometrical relationship of a shaft-hole contact between parts in an assembly-product. However, the difference is that the clearance in a pin-hole contact is not a product variable but a process variable because the locating pin is not part of the product.

\subsection{Process Degradation Model}

The process degradation considered in this assembly process is caused by locator wear process. The effects of tool wear have been considered in literature. Fainguelernt et al. (1986) treated tool wear as a static equivalent error and allocated tolerance to satisfy a worst case requirement. Quesenberry (1988) and Jensen and Vardeman (1993) did not address tolerance issue but considered how to compensate tool wear effect by utilizing in-line observations. Fraticelli et al. (1999) used Sequential Tolerancing Control (STC) to compensate random error resulting from tool wear. However, given the fact that in-line observations were obtained after tool wear actually occurred, what was considered in STC is a realization of the stochastic tool wear process rather than the true stochastic process itself.

If the tool wear is severe, as in the case of machining processes, a frequent compensation or machine tool re-calibration is necessary. In such a situation, the process control strategy using the above adjustment mechanism or STC is recommended. In assembly processes, tool wear is a relatively slow process and its effect on product quality will manifest after a substantial time of 
accumulation. In assembly processes, we can use the initial tolerance range to accommodate the randomness generated from a tool wear process. Including the stochastic tool wear phenomena in the tolerancing scheme is one of the features of process-oriented tolerancing.

The sliding wear model which serves as the governing physical mechanism of tool wear processes was first studied by Archard (1953), where the incremental wear was characterized by

$$
\Delta_{r}=k_{w} \frac{L x}{A}
$$

where $L$ is the loading, $x$ is the slide distance, $A$ is the size of contact area, and $k_{w}$ is a random coefficient. Tang et al. (1988) and Wallbridge and Dowson (1987) concluded that coefficient $k_{w}$ is of a log-normal distribution, determined by material properties and sliding condition. Tang et al. (1988) gave the mean value of $k_{w}$ for alloy-steel materials in a moderate sliding wear condition as $5 \times 10^{-5} \mathrm{~mm}^{3} \mathrm{~N}^{-1} \mathrm{~m}^{-1}$. The other parameters in Eq. (18) are determined by engineering measurements and estimations of actual sliding pairs. Using these basic models, Jin and Chen (2001) established a stochastic degradation model of a tool wear process. The tool wear aggregates when the number of operations increases. The aggregated wear $\Delta_{d}(t)$ at operation $t$ is expressed as

$$
\Delta_{d}(t)=\Delta_{d}(t-1)+\Delta_{r}(t)
$$

where $\Delta_{r}(t)$ is the incremental wear due to operation $t$. Since $k_{w}$ is of a log-normal distribution, $\Delta_{r}(t)$ is also of a lognormal distribution, i.e., $\Delta_{r}(t) \sim \operatorname{LOGNORM}\left(\mu_{\Delta}(t), \sigma_{\Delta}^{2}(t)\right)$. The mean of wearout rate $\mu_{\Delta}$ consists of two components, a constant wear-out rate plus a higher initial wear-out rate that decreases exponentially. The mean of wear-out rate at operation $t$ is assumed to be

$$
\mu_{\Delta}(t)=\mu_{0}+\mu_{1} e^{-\beta t}
$$

where $\mu_{0}+\mu_{1}$ is the initial wear-out rate, $\mu_{0}$ is the constant rate, and $\beta$ determines how fast the wearout will reach its steady state. The clearance change of a pin-hole locating pair can be computed by

$$
d(t)=\delta+\Delta_{d}(t)
$$

where $d(t)$ is the clearance after operation $t$ and the $\delta$ is the initial clearance same as that in Eqs. (6) and (7). This implies that the clearance increases after a pin wears out and the locating variation increases as well. We should substitute the enlarged clearance at time $t_{m}$ into Eqs. (6), (7), and (13) and re-calculate the locating variation. In the next derivations, we make the following assumptions: 
1) the initial clearance $\delta$, the orientation variables $\theta$ and $\kappa$, and the aggregated wear $\Delta_{d}(t)$ are assumed independent of each other; 2) the variance of wear out rate $\sigma_{\Delta}^{2}$ is assumed to be the same for all operations; 3) according to the Central Limit Theorem, the aggregated wear $\Delta_{d}(t)$ will be approximately of a normal distribution after a large enough number of operations. Based on these properties and assumptions, the following relationships can be obtained by substituting Eq. (21) into Eqs. (11), (12), (16) and (17), respectively.

$$
\begin{aligned}
& \sigma_{X, 4-\text { way }}^{2}\left(t_{m}\right)=\mathrm{E}\left[\left(\mathrm{d}+?_{d}\left(t_{m}\right)\right)^{2} \cdot \cos ^{2} \theta\right]=\frac{1}{2} \mathrm{E}\left[\left(\mathrm{d}+?_{d}\left(t_{m}\right)\right)^{2}\right] \\
& \sigma_{Z, 4-\text { way }}^{2}\left(t_{m}\right)=\mathrm{E}\left[\left(\mathrm{d}+?_{d}\left(t_{m}\right)\right)^{2} \cdot \sin ^{2} \theta\right]=\frac{1}{2} \mathrm{E}\left[\left(\mathrm{d}+?_{d}\left(t_{m}\right)\right)^{2}\right] \\
& \sigma_{X, 2-\text { way }}^{2}\left(t_{m}\right)=\mathrm{E}\left[\left(\delta+\Delta_{d}\left(t_{m}\right)\right)^{2} \sin ^{2} \alpha \cdot \kappa^{2}\right]=\sin ^{2} \alpha \cdot \mathrm{E}\left[\left(\delta+\Delta_{d}\left(t_{m}\right)\right)^{2}\right] \\
& \sigma_{Z, 2-\text { way }}^{2}\left(t_{m}\right)=\mathrm{E}\left[\left(\delta+\Delta_{d}\left(t_{m}\right)\right)^{2} \cos ^{2} \alpha \cdot \kappa^{2}\right]=\cos ^{2} \alpha \cdot \mathrm{E}\left[\left(\delta+\Delta_{d}\left(t_{m}\right)\right)^{2}\right]
\end{aligned}
$$

where

$$
\begin{aligned}
& \mathrm{E}\left[\left(\delta+\Delta_{\mathrm{d}}\left(t_{m}\right)\right)^{2}\right]=\mathrm{E}\left[\delta^{2}+2 \delta \Delta_{\mathrm{d}}\left(t_{m}\right)+\Delta_{d}^{2}\left(t_{m}\right)\right] \\
& =\mathrm{E}\left[\delta^{2}\right]+2 \cdot \mathrm{E}[\delta] \cdot \bar{d}\left(t_{m}\right)+\operatorname{Var}\left(\Delta_{\mathrm{d}}\left(t_{m}\right)\right)+\bar{d}\left(t_{m}\right)^{2} \\
& =\frac{5 T_{i}^{2}}{18}+T_{i} \cdot \bar{d}\left(t_{m}\right)+t_{m} \cdot s_{\Delta}^{2}+\bar{d}\left(t_{m}\right)^{2} \\
& =\frac{5}{18} \cdot\left(T_{i}+\frac{9}{5} \bar{d}\left(t_{m}\right)\right)^{2}+t_{m} \cdot s_{\Delta}^{2}+\frac{1}{10} \cdot \bar{d}\left(t_{m}\right)^{2}
\end{aligned}
$$

and $\bar{d}\left(t_{m}\right)=\mathrm{E}\left[\Delta_{d}\left(t_{m}\right)\right]$ is the average aggregated wear.

\subsection{Cost Function}

Various cost functions of tolerances have been proposed for different tolerance synthesis schemes by Wu et al. (1988), where five types of cost-tolerance functions were studied. It was found that the Michael-Siddal function fits the actual data the best while the reciprocal squared function the worst. However, the MichaerSiddal function is a complex function with too many parameters to be determined. Exponential function and reciprocal function are good alternatives with decent data fit and simple function structures. In this paper, we select the reciprocal function as the cost-tolerance function due to its simplicity. That is

$$
C_{T}=\sum_{i=1, \ldots n_{T}} \frac{w_{i}}{T_{i}}
$$

where $T_{i}$ is the $i^{\text {th }}$ tolerance, $i=1,2, \ldots, n_{T}$, and $w_{i}$ is the weight coefficient associated with $T_{i}$. 
Nevertheless, the exponential function can also be used and the general conclusion regarding optimal procedure and optimality will not change. In the above equation, $w_{i}$ determines the relative importance or the relative manufacturing cost associated with each tolerance to be allocated. The relative importance or cost shall be determined by engineering design knowledge or engineering accounting practice.

\subsection{Optimization Formulation and Optimality}

Many optimization schemes including linear optimization, nonlinear optimization, integer optimization, and genetic algorithm have been studied in traditional tolerancing techniques (Ashiagbor et al. 1998; Lee and Woo, 1989; 1990).

In our problem, once these essential process models studied in Section 2.2-2.5 were available, a constrained nonlinear optimization problem is formulated for the multi-station assembly process as

$$
\begin{aligned}
& \mathbf{T}^{*}=\min _{T}\left\{C_{T}(\mathbf{T})\right\} \\
& \text { subject to } g\left(\mathfrak{I}_{Q}, \mathrm{~s}_{s}^{2}\right)=\mathrm{s}_{s}^{2}-\left\|\operatorname{diag}\left(\mathbf{K}_{Y}\right)\right\|_{\infty} \geq 0 \text { for all } 0<t<t_{m} \text { and } T_{i}>0 \forall i
\end{aligned}
$$

where the quality measure is $\mathfrak{I}_{Q}(\mathbf{T}, t)=\left\|\operatorname{diag}\left(\mathbf{K}_{Y}\right)\right\|_{\infty}$ that extracts the diagonal elements of $\mathbf{K}_{Y}$, i.e., $\operatorname{diag}\left(\mathbf{K}_{Y}\right)$ includes the variances of KPC points on the final product. The current choice of constraint function requires that the variations of all KPCs on the final product must be less than a given upper variation limit (i.e., $\sigma_{s}^{2}$ in this formulation). This constraint function is only one of many possible choices, corresponding to a criterion currently used in industrial practice. Other valid measure such as 1-norm and 2-norm may also be used in the constraint function. The use of $\infty$ norm is consistent with the Pareto Principle in quality engineering, i.e., the quality requirement is imposed on the KPCs with relatively large variation values. Our industrial experience indicates that the use of $\infty$-norm is more easily accepted by industrial practitioners.

It can also be concluded (based on theorems in Zangwill (1967)) that this formulation (28) achieves the global optimality because the cost-function is convex and the constraint function is a concave quadratic function. Any available non-linear programming software package can be used to solve this optimization problem. 


\section{EXAMPLE}

The automotive assembly process of a side aperture inner panel is used to illustrate the tolerancing procedure of a multi-station process. This assembly process, shown in Fig. 11, is conducted at three assembly stations (Station I, II, III) and the product is inspected at the measurement station. The final subassembly inner-panel-complete (Fig. 11 (c)) consists of four components: Apillar inner panel, B-pillar inner panel, rail roof side panel, and rear quarter inner panel. At Station I (Fig. 11(a)), the Apillar inner panel and the B-pillar inner panel are joined together. The subassembly "A-pillar+B-pillar" is welded with the rail roof side panel at Station II (Fig. 11(b)). The subassembly of the first three panels is then assembled with the rear quarter inner panel at Station III (Fig. 11(c)). Finally, measurements are taken at KPC points (marked in Fig. 11(d) as $\mathrm{M}_{1}-\mathrm{M}_{10}$ ) by using either off-line or in-line measurement systems such as CMM or OCMM. The nominal design positions of the fixture locators (PLPs) and KPC points in 2-D (X-Z coordinates) are given in Table 2 and Table 3, respectively.

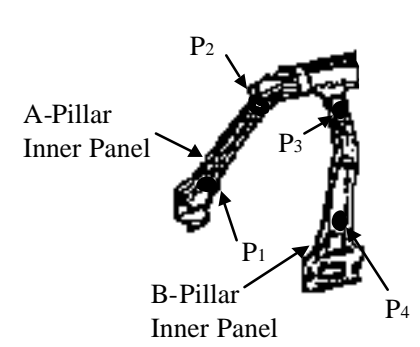

(a) Station I
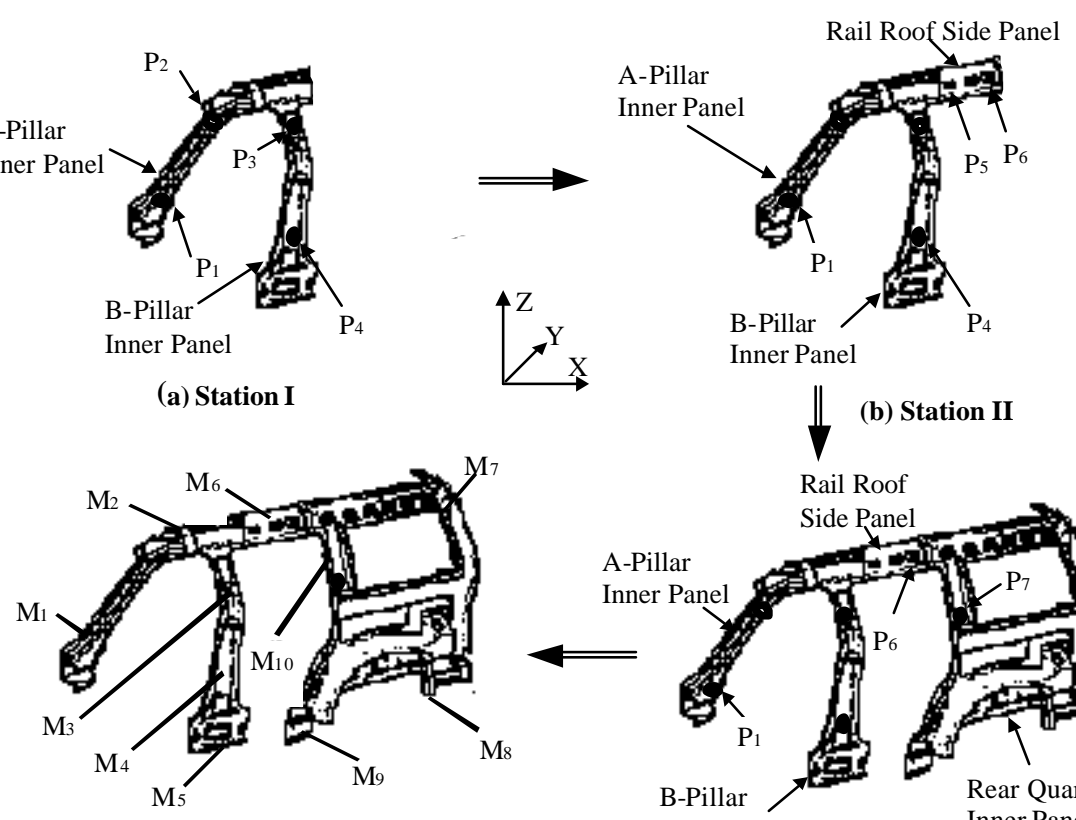

(d) Measurement: KPC Points

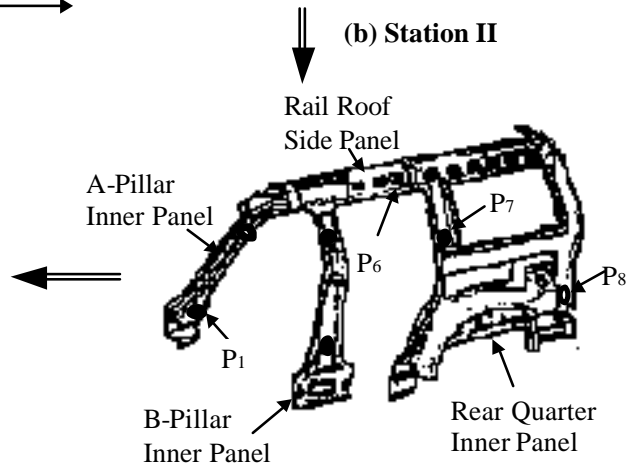

(c) Station III

Figure 11. Side aperture inner panel assembly 
Table 2. Coordinates of fixture locators (PLPs) from Fig. 11. (Units: mm)

\begin{tabular}{|c|c|c|c|c|}
\hline PLP & $\mathrm{P}_{1}$ & $\mathrm{P}_{2}$ & $\mathrm{P}_{3}$ & $\mathrm{P}_{4}$ \\
\hline$(\mathrm{X}, \mathrm{Z})$ & $(367.8,906.05)$ & $(667.47,1295.35)$ & $(1301,1368.89)$ & $(1272.73,537.37)$ \\
\hline $\mathrm{PLP}$ & $\mathrm{P}_{5}$ & $\mathrm{P}_{6}$ & $\mathrm{P}_{7}$ & $\mathrm{P}_{8}$ \\
\hline$(\mathrm{X}, \mathrm{Z})$ & $(1470.71,1640.40)$ & $(1770.50,1702.62)$ & $(2941.42,1691.31)$ & $(2120.32,1402.83)$ \\
\hline
\end{tabular}

Table 3. Coordinates of KPCs from Fig. 11 (d). (Units: mm)

\begin{tabular}{|c|c|c|c|c|c|}
\hline $\mathrm{KPC}$ & $\mathrm{M}_{1}$ & $\mathrm{M}_{2}$ & $\mathrm{M}_{3}$ & $\mathrm{M}_{4}$ & $\mathrm{M}_{5}$ \\
\hline$(\mathrm{X}, \mathrm{Z})$ & $(271.50,905)$ & $(565.7,1634.7)$ & $(1289.7,1227.5)$ & $(1306.5,633.5)$ & $(1244.5,85)$ \\
\hline $\mathrm{KPC}$ & $\mathrm{M}_{6}$ & $\mathrm{M}_{7}$ & $\mathrm{M}_{8}$ & $\mathrm{M}_{9}$ & $\mathrm{M}_{10}$ \\
\hline$(\mathrm{X}, \mathrm{Z})$ & $(1604.5,1781.8)$ & $(2884.8,1951.5)$ & $(2743.5,475.2)$ & $(1838.4,226.3)$ & $(1979.8,1459.4)$ \\
\hline
\end{tabular}

Before conducting process-oriented tolerancing, we need to establish a state space variation model for this particular panel assembly process. This process has $N=4$. Since fixture used on the inspection station is considered well maintained and calibrated with much higher repeatability than those on a regular assembly station, the input variation of fixture locators on the measurement station is neglected. The deviation inputs from fixtures on three assembly stations, $\mathbf{P}(1), \mathbf{P}(2)$, and $\mathbf{P}(3)$, are included. The state space variation model is

$$
\left\{\begin{array}{l}
\mathbf{X}(1)=\mathbf{B}(1) \mathbf{P}(1)+\mathbf{W}(1) \\
\mathbf{X}(k)=\mathbf{A}(k-1) \mathbf{X}(k-1)+\mathbf{B}(k) \mathbf{P}(k)+\mathbf{W}(k), k=2,3 \\
\mathbf{X}(4)=\mathbf{A}(3) \mathbf{X}(3)+\mathbf{W}(4) \\
\mathbf{Y}=\mathbf{C X}(4)+\mathbf{V}
\end{array}\right.
$$

where A's, B's, and C can be obtained following the procedure outlined in Ding et al. (2000).

\subsection{Tolerance allocation when tooling degradation is not considered}

There are twelve tolerance variables of clearance $T_{1} \sim T_{12}$ to be allocated in this three-station process (each station has four pin-hole locating pairs). It is assumed that all process variables are subject to the same manufacturing cost, that is, $w_{i}=1$ for $i=1,2, \ldots, 12$ in Eq. (27). The designer requires that the final product (the inner-panel-complete) must have Six-Sigma value less than 1.5 $\mathrm{mm}$ at all KPCs, namely $\sigma_{s}^{2}=\left(\frac{1.5}{6}\right)^{2}$ in Eq. (28). From industrial practice, it is known that the tolerance of a clearance is usually larger than $0.01 \mathrm{~mm}$. Thus, the initial tolerance is then picked up 
from the interval $[0.01,2] \mathrm{mm}$. The procedure for tolerance allocation is shown in the following flow chart (Fig. 12).

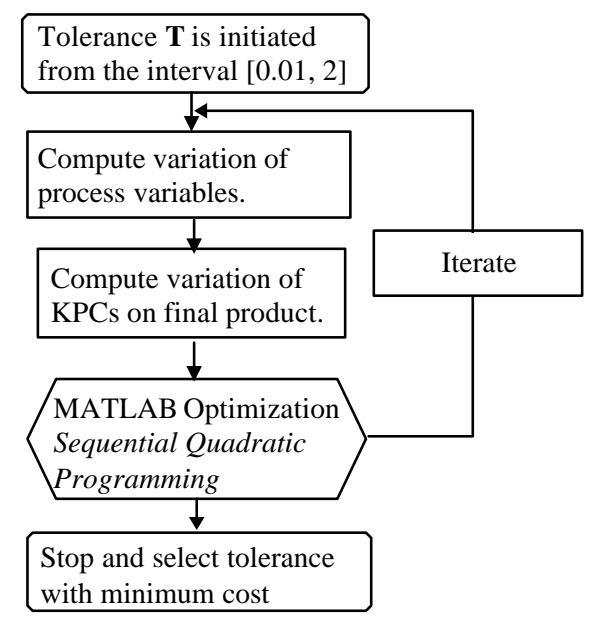

Figure 12. Tolerance allocation without degradation model

The optimization problem is solved using MATLAB function fmincon which uses a Sequential Quadratic Programming (SQP) method (MATLAB, 1999). The SQP algorithm operates by solving a sequence of quadratic sub-problems. Each quadratic sub-problem represents solving an approximation to the Langrangian function. The SQP is chosen because it is a very efficient nonlinear programming algorithm and is commercially available. The algorithm can converge to the global optimum owing to the quadratic nature of the optimization problem in Eq. (28). Due to the availability of analytical models developed in Section 2, the time-consuming Monte Carlo simulation can be avoided when the variation of process variables were obtained. The program converges in minutes and yields the optimal tolerance after 290 iterations. The optimally allocated tolerances for these process variables are listed in Table 4.

Table 4. Tolerances without tooling degradation. (Unit : $\mathrm{mm}$ )

\begin{tabular}{|c|c|c|c|c|c|c|c|c|c|c|c|}
\hline$T_{1}$ & $T_{2}$ & $T_{3}$ & $T_{4}$ & $T_{5}$ & $T_{6}$ & $T_{7}$ & $T_{8}$ & $T_{9}$ & $T_{10}$ & $T_{11}$ & $T_{12}$ \\
\hline 0.21 & 0.36 & 0.19 & 0.31 & 0.30 & 0.42 & 0.63 & 0.36 & 0.34 & 0.34 & 0.34 & 0.32 \\
\hline
\end{tabular}

Compared with current industry practice, where the tolerance of locating clearance is allocated uniformly for all locating pairs, the proposed approach no longer allocates tolerances uniformly. This non-uniformity is consistent with process sensitivity, that is, the more variation a process variable contributes to the final product, the tighter the corresponding tolerance should be. It is 
difficult for an empirical approach to determine which tolerance should be tight. As a result, either the cost is higher or the variation of the final product is above the threshold using empirical approaches. In other words, optimality is difficult to achieve.

\subsection{Tolerance allocation with consideration of tooling degradation}

Under this circumstance, tolerances are allocated at the beginning of production while quality criteria are checked for all products produced by the degraded process. The procedure for tolerance allocation with consideration of tooling degradation model is shown in Fig. 13.

Optimization is still solved using MATLAB function fmincon but with the implementation of the tooling degradation model. Based on industry experience, parameters needed in the degradation model such as operation rate, maintenance period, and pin wear-out rate are listed in Table 5. The program converges and yields the optimal tolerance after almost the same number of iterations as in Section 3.1. The new tolerances become tighter and are shown in Table 6.

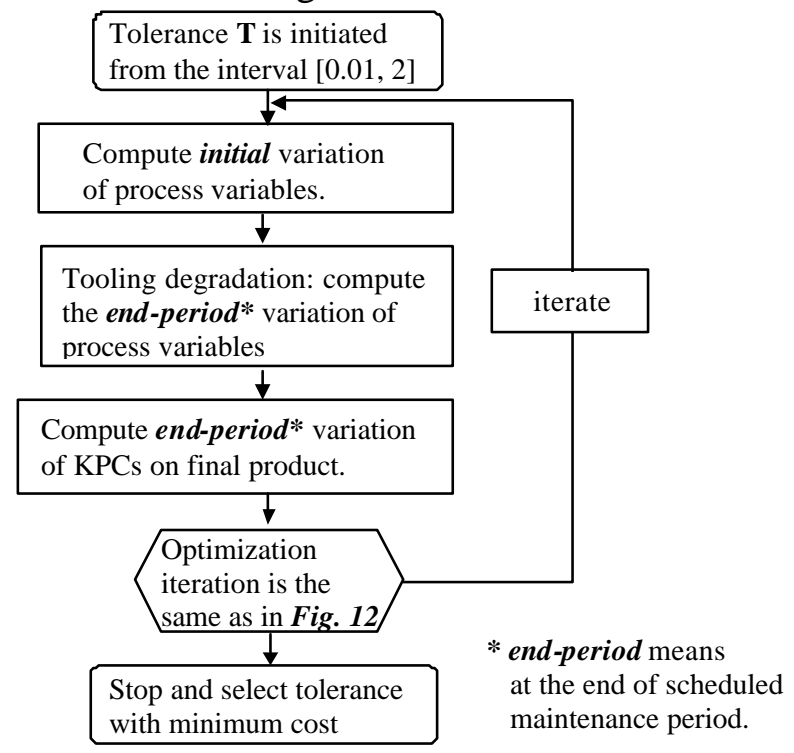

Figure 13. Tolerance allocation with degradation model

Table 5. Parameters in degradation model

\begin{tabular}{|c|c|c|c|c|c|}
\hline$\mu_{0}(\mathrm{~mm})$ & $\mu_{1}(\mathrm{~mm})$ & $\beta$ & $\sigma_{\Delta}(\mathrm{mm})$ & $t_{m}$ & operations/day \\
\hline $5 \times 10^{-7}$ & $1 \times 10^{-6}$ & $1 \times 10^{-3}$ & $5 \times 10^{-5}$ & 6 months & 500 \\
\hline
\end{tabular}


Table 6. Tolerances with tooling degradation. (Unit : mm)

\begin{tabular}{|c|c|c|c|c|c|c|c|c|c|c|c|}
\hline$T_{1}$ & $T_{2}$ & $T_{3}$ & $T_{4}$ & $T_{5}$ & $T_{6}$ & $T_{7}$ & $T_{8}$ & $T_{9}$ & $T_{10}$ & $T_{11}$ & $T_{12}$ \\
\hline 0.16 & 0.31 & 0.14 & 0.25 & 0.23 & 0.34 & 0.58 & 0.26 & 0.30 & 0.27 & 0.28 & 0.26 \\
\hline
\end{tabular}

\subsection{Compa rison and Discussion}

In the current automotive industry, tolerances are uniformly set to be $0.25 \mathrm{~mm}$ for all clearances. Substituting these tolerances into the system model described in Sections 2, the maximum SixSigma values of KPCs both at the beginning of production and after half year production are listed in Table 7. Although the assigned tolerance can produce qualified products at the beginning of a production period, many out-of-specification products will be fabricated after tooling elements have degraded.

Table 7. Maximum $6 \sigma$ of KPCs for $0.25 \mathrm{~mm}$ tolerance

\begin{tabular}{|c|c|c|}
\hline Beginning & Half Year & Specified \\
\hline $6 \sigma=1.44 \mathrm{~mm}$ & $6 \sigma=1.77 \mathrm{~mm}$ & $6 \sigma=1.50 \mathrm{~mm}$ \\
\hline
\end{tabular}

Furthermore, the manufacturing cost of different cases, represented by the summation of reciprocals of all the tolerances (Eq. 27) are compared in Table 8. When degradation is not considered, tolerances are allocated non-uniformly and result in a ma nufacturing cost reduction of $20.6 \%$, compared to the uniform $0.25 \mathrm{~mm}$ tolerance scheme. When process degradation is considered, product quality is ensured throughout the production without increasing manufacturing cost from that of the uniform $0.25 \mathrm{~mm}$ tolerance scheme. Since defective product will be unavoidably produced under the scheme of uniform $0.25 \mathrm{~mm}$ tolerance, the actual cost is even higher for the empirical method when the quality-loss related costs such as rework, labor, and material waste are counted. Overall, process-oriented tolerance allocation can deliver high quality product in comparably lower cost.

Table 8. Comparison of manufacturing cost of different scenarios

\begin{tabular}{|c|c|c|c|}
\hline Conditions & Without degradation & With degradation & uniform $0.25 \mathrm{~mm}$ \\
\hline Cost & 38.1 & 47.9 & 48 \\
\hline
\end{tabular}




\section{CONCLUSIONS}

This paper presents a systematic methodology for process-oriented tolerancing in multi-station manufacturing processes, with a detailed technical development conducted in the context of multistation assembly processes. The concept of process-oriented tolerancing expands current tolerancing practices, which focused on bounding errors related to product variables, to explicitly include process variables. The resulting methodology expands the concept of "part interchangeability" into "process interchangeability," which is critical in increasing requirements related to the suppliers selection and benchmarking or outsourcing.

Process-oriented tolerancing includes not only the information of product design but also a much broader category of information regarding process design and quality requirements. The processoriented approach integrates design and manufacturing and can thus, optimally allocate tolerances to process variables of the whole system with remarkably low manufacturing cost. Furthermore, the process-oriented approach can integrate stochastic process information (which is usually difficult to include in traditional product-oriented method) in tolerance optimization so that quality satisfaction is ensured for the entire process life-cycle service without raising manufacturing cost. Thus, the shift to the process-oriented paradigm is a critical technological trend as being pointed out by Thurow (1992), "In the future sustainable competitive advantage will depend more on new process technologies and less on new product technologies."

\section{REFERENCES:}

1. Agrawal, R., Lawless, J.F. and Mackay, R.J., 1999, "Analysis of Variation Transmission in Manufacturing Processes - Part II," Journal of Quality Technology, 31, 143 - 154.

2. Archard, J. F., 1953, "Contact and rubbing of flat surfaces," Journal of Applied Physics, 24, 981-988.

3. Ashiagbor, A., Liu, H.-C., and Nnaji, B.O., 1998, "Tolerance Control and Propagation for the Product Assembly Modeller," International Journal of Production Research, 36, 75-93.

4. Bjorke, O., 1989, Computer Aided Tolerancing, Tapir Publishers, Trondheim, Norway.

5. Cai, W., Hu, S.J., Yuan, J.X., 1996, "Deformable Sheet Metal Fixturing: Principles, Algorithms, and Simulations," ASME Journal of Manufacturing Science and Engineering, 118, 318-324.

6. Camelio, A.J., Hu, S.J., and Ceglarek, D.J., 2001, "Modeling Variation Propagation of Multistation Assembly Systems with Compliant Parts," Proceedings of the 2001 ASME Design 
Engineering Technical Conference, Pittsburgh, PA, September 9-12.

7. Ceglarek, D. and Shi, J., 1995, "Dimensional Variation Reduction for Automotive Body Assembly," Manufacturing Review, 8, 139 - 154.

8. Ceglarek, D. and Shi, J., 1997, "Tolerance Analysis for Sheet Metal Assembly Using a Beambased Model," ASME Design Engineering Division Publication, 94, 153-159.

9. Ceglarek, D., Shi, J., and Wu, S.M., 1994, "A Knowledge-Based Diagnostic Approach for the Launch of the Auto-Body Assembly Process," ASME Journal of Engineering for Industry, 116, $491-499$.

10. Chase, K. W. and Parkinson, A. R., 1991, "A Survey of Research in the Application of Tolerance Analysis to the Design of Mechanical Assemblies," Research in Engineering Design, 3, 23 - 37.

11. Choudhuri, S.A. and DeMeter, E.C., 1999, "Tolerance Analysis of Machining Fixture Locators," ASME Journal of Manufacturing Science and Engineering, 121, 273 - 281.

12. Cunningham, T. W., Matripragada, R., Lee, D. J, Thornton, A. C., and Whitney D. E., 1996, "Definition, Analysis, and Planning of a Flexible Assembly Process," Proceedings of 1996 Japan/USA Symposium on Flexible Automation, 2, 767 - 778.

13. DCS, 2000, 3-D Variation Simulation, Dimensional Control Systems, Inc., 580 Kirts Blvd, Suite 309, Troy MI, 48084.

14. Ding, Y., Ceglarek, D. and Shi, J., 2000, "Modeling and Diagnosis of Multistage Manufacturing Process: Part I State Space Model," Proceedings of 2000 Japan-USA Symposium on Flexible Automation, July 23-26, Ann Arbor, MI, 2000JUSFA-13146.

15. Djurdjanovic, D., and Ni, J., 2001, "Linear State Space Modeling of Dimensional Machining Errors," Transactions of NAMRI/SME, XXIX, 541-548.

16. Fainguelernt, D., Weill, R., and Bourdet, P., 1986, "Computer Aided Tolerancing and Dimensioning in Process Planning," Annals of the CIRP, 35/1, 381-386.

17. Fraticelli, B.M.P., Lehtihet, E.A., and Cavalier, T.M., 1999, “Tool-wear Effect Compensation Under Sequential Tolerance Control," International Journal of Production Research, 37, 639651.

18. Jeang, A., 1994, “Tolerancing design: Choosing Optimal Tolerance Specifications in the Design of Machined Parts," Quality and Reliability Engineering International, 10, 27-35.

19. Jensen, K.L. and Vardeman, S.B., 1993, "Optimal Adjustment in the Presence of Deterministic Process Drift and Random Adjustment Error," Technometrics, 35, 376-389.

20. Jin, J. and Chen, Y., 2001, "Quality and Reliability Information Integration for Design Evaluation of Fixture System Reliability," Quality and Reliability Engineering International, 17, 355-372.

21. Jin, J. and Shi, J., 1999, "State Space Modeling of Sheet Metal Assembly for Dimensional Control," ASME Journal of Manufacturing Science \& Engineering, 121, 756 - 762.

22. Lawless, J.F., Mackay, R. J. and Robinson, J.A., 1999, "Analysis of Variation Transmission in 
Manufacturing Processes - Part I," Journal of Quality Technology, 31, 131 - 142.

23. Lee, W-J, Woo, T.C., 1989, "Optimum Selection of Discrete Tolerances," ASME Journal of Mechanisms, Transmissions, and Automation in Design, 111, 243 - 251.

24. Lee, W-J, Woo, T.C., 1990, "Tolerances : Their Analysis and Synthesis," ASME Journal of Engineering for Industry, 112, 113 - 121.

25. Liu, S.C., Hu, S.J., and Woo, T.C., 1996, "Tolerance Analysis for Sheet Metal Assemblies," ASME Journal of Mechanical Design, 118, 62 - 67.

26. Mantripragada, R. and Whitney, D. E., 1999, "Modeling and Controlling Variation Propagation in Mechanical Assemblies Using State Transition Models," IEEE Transactions On Robotics and Automation, 15, 124-140.

27. MATLAB, 1999, Optimization Toolbox User's Guide, Version 5, The MathWorks Inc., Natick, MA.

28. Mou, J., 1997, “A Systematic Approach to Enhance Machine Tool Accuracy for Precision Manufacturing," International Journal of Machine Tools Manufacturing, 37, 669-685.

29. Ngoi, B.K.A and Ong, C. T., 1993, “A Complete Tolerance Charting System," International Journal of Production Research, 31, 453-469.

30. Ngoi, B.K.A and Ong, C. T., 1998, "Product and Process Dimensioning and Tolerancing Techniques: A State-of-the-Art Review," International Journal of Advanced Manufacturing Technology, 14, 910-917.

31. Ngoi, B.K.A and Ong, J.M., 1999, "A Complete Tolerance Charting System in Assembly," International Journal of Production Research, 37, 2477-2498.

32. Quesenberry, C.P., 1988, "An SPC Approach to Compensating a Tool-Wear Process," Journal of Quality Technology, 20, 220-229.

33. Rong, Y. and Bai, Y., 1996, "Machining Accuracy Analysis for Computer-aided Fixture Design Verification," ASME Journal of Manufacturing Science and Engineering, 118, 289 - 299.

34. Roy, U., Liu, C. R., and Woo, T.C., 1991, "Review of Dimensioning and Tolerancing: Representation and Processing," Computer-Aided Design, 23, 466-483.

35. Shiu, B., Ceglarek, D., and Shi, J., 1996, "Multi-Station Sheet Metal Assembly Modeling and Diagnostics," NAMRI/SME Transactions, XXIV, 199 - 204.

36. Slocum, A. H., 1992, Precision Machine Design, Prentice Hall, New Jersey.

37. Soons, J.A., Theuws, F.C., Schellekens, P.H., 1992, "Modeling the Errors of Multi-Axis Machines: A General Methodology," Precision Engineering, 14, 5-19.

38. Suri, R. and Otto, K., 1999, "Variation Modeling for a Sheet Stretch Forming Manufacturing System," Annals of the CIRP, 48, 397 - 400.

39. Tang, L. C., Goh, C. J., and Lim, S. C., 1988, “On the Reliability of Components Subject to Sliding Wear- A first Report," Sliding Wear, 22, 1177-1181.

40. Thurow, L., 1992, Head to Head: the Coming Economic Battle Among Japan, Europe, and 
America, Morrow, Inc., New York.

41. Veitschegger, W.K. and Wu, C., 1986, "Robot Accuracy Analysis Based on Kinematics," IEEE Journal of Robotics and Automation, RA-2, 171-179.

42. Voelcker, H.B., 1998, "The Current State of Affairs in Dimensional Tolerancing," Integrated Manufacturing Systems, 9, 205 - 217.

43. VSA, 1998, VSA-3D Release 12.5 User Manual, Variation System Analysis, Inc., 300 Maple Park Boulevard, St. Clair Shores, MI 48081.

44. Wallbridge, N. C. and Dowson, D., 1987, "Distribution of Wear Rate Data and Statistical Approach to Sliding Wear Theory," Wear, 119, 295-312.

45. Whitney, D.E., Gilbert, O.L., and Jastrzebski, M., 1994, "Representation of Geometric Variations Using Matrix Transforms for Statistical Tolerance Analysis in Assemblies," Research in Engineering Design, 6, 191 - 210.

46. Wu, Z., ElMaraghy, W.H. and ElMaraghy, H.A., 1988, "Evaluation of Cost-Tolerance Algorithms for Design Tolerance Analysis and Synthesis," Manufacturing Review, 1, 168 - 179.

47. Zangwill, W. I., 1967, Nonlinear Programming: A Unified Approach, Prentice-Hall, Englewood Cliffs, N.J.

48. Zhang, G., 1996, "Simultaneous Tolerancing for Design and Manufacturing," International Journal Of Production Research, 34, 3361-3382.

49. Zhang, H. (ed.), 1997, Advanced Tolerancing Techniques, John Wiley \& Sons, Inc., New York. 